\title{
Non-Invasive Urothelial Neoplasm
}

National Cancer Institute

\section{Source}

National Cancer Institute. Non-Invasive Urothelial Neoplasm. NCI Thesaurus. Code C39854.

A non-invasive neoplasm affecting the urothelium. 